\title{
FIRST LANGUAGE ATTRITION \\ IN VOICE ONSET TIMES \\ IN ANGLOPHONE EXPATRIATES \\ RESIDING IN THE CZECH REPUBLIC
}

Brno Studies in English

Volume 46, No. 2, 2020

ISSN 0524-6881 | e-ISSN 1805-0867

https://doi.org/10.5817/BSE2020-2-3

\section{MAGDA SUČKOVÁ}

\begin{abstract}
The present article investigates first language attrition in the domain of phonetics in Anglophone expatriates (the British and Americans) residing long-term in the Czech Republic. The focus of the investigation is the influence of Czech and Czech-accented English plosives on the expatriates' native English ones. The results replicate previous findings, showing shortening of voice onset times in the expatriates' fortis plosives. As regards lenis plosives, the expatriates exhibited more frequent prevoiced realization than the controls. Thus, the findings of the present investigation indicate that even speakers of a prestigious language, who by no means lack the opportunity to use L1 both at home and at work, are not immune to L1 attrition or cross-linguistic influence.
\end{abstract}

Key words

Language attrition; voice onset times; fortis plosives; phonetics; sociolinguistics

\section{Introduction}

It is not unusual for a person who has been residing abroad for a period of time to observe changes in their first language (L1) or to receive comments from their family and friends back at home about sounding "different". These nonpathological changes, referred to as reverse cross-linguistic influence (Jarvis and Pavlenko 2008) or first language attrition (Schmid 2011), are caused by the acquisition and use of an L2 on the one hand, and the limited use of and exposure to the L1 on the other (Schmid 2011). To date, L1 attrition has been documented to operate on all linguistic levels (Schmid and de Bot 2004; Schmid 2016), including that of phonetics. In fact, as early as in 1935 the prominent Czech linguist and co-founder of the Prague School of Linguistics Vilém Mathesius observed that "Czechs living in Slovakia seem to be more prone to š $(/ S /)$ pronunciation in foreign-origin words due to the influence of the Slovak language" (1935: 102, translation mine). However, he did not investigate this phenomenon further, and the first experimental studies on L2 $\rightarrow$ L1 influence in the domain of phonetics started appearing only about 50 years later. These more recent studies conducted on L1 attrition in phonetics have shown that this process manifests itself on both the global accent of the long-term immigrants, to the degree that some may no longer be perceived as native speakers of their L1 (de Leeuw 2008; Bergmann et 
al. 2016), as well as on the level of fine phonetic detail, such as voice onset times (VOTs) in plosives (Flege 1987; Major 1992; Sancier and Fowler 1997), which also present the focus of this article.

In the present article I first describe the concept of voice onset time (VOT), next I review the up-to-date literature on VOTs in L1 attrition research, then I discuss the differences between the Czech and English VOTs in plosives and formulate the hypotheses as to Czech $\rightarrow$ English influence, and finally I present and discuss the results of my investigation into the VOTs of Anglophone expatriates living in the Czech Republic.

\section{Literature review}

\subsection{Voice onset time - definition and findings in L1 attrition research}

Voice onset time (VOT) is an acoustic feature of plosives which has been shown to be one of the most effective correlates of the lenis/fortis distinction (Skarnitzl 2011). Lisker and Abramson (1964: 387) defined VOT as "timing relation between voice onset and the release of occlusion." In other words, VOT is "the interval (in $\mathrm{ms}$ ) between the release of a stop closure, and the onset of voicing for a following voiced segment" (Docherty 1992: 13). In bilingualism research, VOT is now a standardly utilized phonetic variable due to its considerable interlanguage variability, proneness to cross-linguistic influence, and relative straightforwardness in measurement (Thomas 2011).

To date, it has been shown in several studies that VOTs in voiceless plosives are subject to L2 $\rightarrow$ L1 cross-linguistic influence in contexts where the immigrant's L1 and the majority language of the country of residence (i.e. the immigrant's L2) feature different VOT patterns. Flege and Hillenbrand (1984) demonstrated that the French living in the USA exhibited longer VOTs than their counterparts living in France due to their daily use of and exposure to English long-lag VOTs. By contrast, American immigrants married to French husbands and living in France displayed significantly shorter VOTs in their L1 English / $t$ / than the control groups with no or much smaller experience with the French language (Flege 1987). Major (1992) studied the influence of short-lag Brazilian Portuguese voiceless plosives on the long-lag English ones; the five L1 speakers of English residing in Brazil "to a greater or lesser extent" (1992: 200) exhibited shortening of their L1 English VOTs in /p, t, k/; the degree of this shortening was shown to correlate with L2 proficiency and was more prominent in casual speech style. As regards the contact of English and Brazilian Portuguese, the influence goes both ways, as the following studies indicate. Sancier and Fowler's (1997) case study featured a single participant, namely a native speaker of Brazilian Portuguese with advanced command of English, who lived in both Brazil and the USA, alternating between the two regularly. In both languages, the plosives under investigation $(/ \mathrm{p}, \mathrm{t} /)$ mirrored the recent phonetic environment, i.e. the participant's L1 VOTs were longer after staying in the USA, and shorter after staying in Brazil, hinting on the temporary nature of the L2-induced phonetic 
changes. In addition, Kupske and Alvez (2016) showed that VOTs in L1 Brazilian Portuguese voiceless plosives lengthen in correlation with the length of stay in the L2 environment, namely in London. Finally, in a case study of Dutch-English bilingual monozygotic twins (Mayr, Price, and Mennen 2012), the twin residing in the USA displayed longer VOTs in her L1 Dutch voiceless plosives than the twin residing in the Netherlands.

The research regarding cross-linguistic influence on lenis plosives, however, seems to be much scarcer. In the case study of monozygotic twins cited above (Mayr, Price, and Mennen 2012), the twin residing in the USA did not exhibit any deviation from the Dutch norm of prevoicing word-initial voiced plosives. The authors explain this finding by the importance of prevoicing as a cue for the identification of Dutch voiced plosives. Another study looking at both voiceless and voiced plosives is that of Stoehr et al. (2017), which examined VOT patterns in L1German-L2Dutch and L1Dutch-L2German bilinguals living in the Netherlands. The two groups differed with respect to L2-use proliferation in different realms: L1 German speakers were exposed to their L2 (Dutch) both at home and at work, whereas L1 Dutch speakers were exposed to their L2 (German) only at home. The authors found evidence for L1 attrition only in L1German-L2Dutch speakers, who exhibited shorter than native-like aspiration in L1-German voiceless plosives under the influence of Dutch. However, their voiced plosives did not feature a higher percentage of prevoicing - or negative VOTs - typical of Dutch plosives, and remained native-like, i.e. short-lag. Thus, the L1German group opted for VOT patterns requiring less effort to pronounce (Stoehr et al. 2017). The L1Dutch-L2German group did not exhibit signs of L1 attrition in neither voiced nor voiceless plosives, lending support to the claim that "[w]ithout frequent and diverse exposure to the L1, the more prominent L2 is likely to impact on the L1 phonetic categories" (Stoehr et al. 2017: 504).

In conclusion, while VOTs of voiceless plosives seem to be very "open" to cross-linguistic influence, VOTs of their phonologically voiced counterparts do not appear to exhibit the same characteristics due to various other constrains.

\subsection{Theoretical frameworks explaining reverse cross-linguistic influence in phonetics}

The findings concerning the plasticity of VOTs are usually interpreted in terms of Speech Learning Model (SLM), an influential theoretical framework proposed by Flege (e.g. 2002). This model posits the existence of a common phonological space in which the phonic elements of a bilingual's L1 and L2 interact with each other. L1 and L2 phonemes identified as similar by the bilingual speaker merge in the process of phonetic category assimilation, becoming more similar to each other, but differing from the monolingual norms of the two languages. This process has been well documented in the shortening/lengthening of voiceless plosives under the influence of the surrounding L2. Flege (e.g. 2002) postulates one more process at play, namely that of phonetic category dissimilation, when an L2 sound is identified as non-existent in the L1 and, as a result, forms a distinct category in the phonological space. In order to maintain the L1 and L2 
contrast, however, both L1 and L2 sounds drift away from the respective monolingual norms to more extreme positions. This can, in fact, be seen as a form of hyper-correction.

In terms of global accent, this reconstituting of multiple phonetic elements in the shared phonetic space may then lead to the overall "foreign-accentedness" in both L2 and L1 of a bilingual. However, as we have seen in the review of literature on VOT research, the processes of phonetic category assimilation and dissimilation may be overridden by the tendency towards less laborious pronunciation (as in Stoehr et al. 2017) or the importance of a certain phonetic feature as a cue (as in Mayr, Price, and Mennen 2012).

It should be noted here that Flege's Speech Learning Model is not the only theoretical framework positing the mutual interaction of L1 and L2 elements in a common space. This notion is also central to e.g. Cook's (2002) somewhat broader concept of multicompetence, which refers to "language super-system" (Cook 2003: 2) formed by the various languages of a multilingual person.

Finally, there is another theoretical framework which bears mentioning in connection with phonetic changes in a person's L1 while living in an L2 country, namely the Communication Accommodation Theory (CAT, previously known as Speech Accommodation Theory). This theory, albeit rarely discussed in the context of L1 attrition (a notable exception being Dostert 2009), may be key in explaining language attrition phenomena in speakers who continue using their L1 upon immigration in interactions with non-native speakers (i.e. learners or L2 users) of this language; with Anglophone expatriates being the point in case.

The Communication Accommodation Theory states that "[i]n interaction, individuals adjust their communicative behavior [...] based on their evaluation of their fellow interactant's communicative characteristics, as well as their own desire to maintain a positive personal and social identity." (Gasiorek, Giles, and Soliz 2015: 1). The adjustments, i.e. accommodation, are realized through the strategies of convergence, divergence, and maintenance. Convergence refers to the adjustment in one's communicative characteristics (such as pronunciation, speech rate, etc.) to become more similar to those of the interlocutor; divergence, on the other hand, refers to the increasing of dissimilarities in communicative characteristics (Dragojevic and Giles 2014). Finally, maintenance refers to not making any changes to one's communicative style, i.e. retaining the same characteristics throughout the encounter (Bourhis, as cited in Giles and Ogay 2007). Apart from the classification of the accommodation strategies CAT also provides explanation as to why speakers adopt them. The speaker may converge when they desire to obtain social approval, decrease social distance, and/or to achieve a high level of communication efficiency. They may maintain communicative patterns or diverge if they desire to increase or maintain social distance, or desire to highlight a particular group membership (Beebe and Giles 1984; Gasiorek, Giles, and Soliz 2015; Giles and Ogay 2007).

How may CAT be relevant in explaining L1 attrition in Anglophone expatriates? Upon arrival in the host country, native speakers of English may have no knowledge of the country's language, so they cannot converge to the locals using the L2. Often, however, the host country inhabitants (especially the city dwellers) 
may be more than happy to converge to the foreigner, seizing the opportunity to practice their L2 English, even in situations when the Anglophone foreigner may actually have sufficient local language proficiency. The foreigner, wishing to be accepted and to enhance the communication, in turn converges towards the interlocutor's L2 English, possibly speaking more slowly, switching to the standard, and avoiding low frequency lexical items. In other words, the native speaker of English may retort to what has been termed "foreigner talk", "an attempt to improve communicative efficiency by mimicking the speech of the foreigner" (Snow, van Eden, and Muysken 1981: 90). Paradoxically, the native speakers of English then find themselves utilizing foreigner talk in a country where, in fact, they are the foreigner. This accommodation strategy, utilized to appear more likeable or more easily understood, may lead to the drift of certain phonetic characteristics towards those of the L2 users' as well.

Dostert (2009) speculated that the type of convergence described above may only last a relatively short period of time upon the arrival to the host country; once the Anglophone expatriate builds their social network, they may no longer need to engage in accommodation seeking social approval. By then, however, the expatriates may have become habitualized to converging and the modifications may present a more or less permanent fixture, reversible only by a prolonged stay in the L1 country (as shown by Sancier and Fowler 1997). Native speaker teachers of English may be particularly vulnerable to L1 attrition (as also pointed out by Dostert 2009, and Porte 1999) due to another form of convergence termed "teacher talk" whereby the teachers adjust their L1 according to the language proficiency of their students (e.g. Chaudron 1988). It is worth noting here that exposure to non-native L1 input (especially of lower-proficiency users) can hardly substitute the richness of native country input.

In summary, the native speakers of English who choose to live and work in a non-Anglophone country may experience L2 $\rightarrow$ L1 phonetic interference through the processes of assimilation and dissimilation of phonetic elements in the shared phonetic space as a result of learning and using the host country's language, and, at the same time, through the communication accommodation strategy of convergence when adjusting L1 to that of non-native interlocutors. This non-native variety they converge to is, in fact, already influenced by the local language, as postulated by the Speech Learning Model.

\subsection{VOTs in English and Czech plosives}

As the purpose of the article is to investigate the Czech plosive VOTs influence on the English ones, it is important to provide detailed characteristics of VOTs in the two languages.

The English word-initial pre-vocalic fortis plosives are aspirated in stressed syllables. In other words, they feature a long-lag positive VOT, which means that the vocal folds start vibrating several tens of $\mathrm{ms}$ after the release of the closure (Docherty 1992). Docherty (1992: 116) reported the range of duration between $18-127$ ms depending on the plosive, with / $\mathrm{p} /$ featuring the shortest and $/ \mathrm{k} /$ the longest duration of VOTs. In the Czech language, the voiceless plosives 
feature a short-lag VOT, in which vocal fold vibration starts shortly after the release (Machač 2006), i.e. there is no aspiration as in the English fortis plosives, which often leads to L1 $\rightarrow$ L2 crosslinguistic interference in Czech users of English (Pospísilová 2011; Melen 2010).

As regards lenis plosives, the situation is not as clear-cut. The English word-initial pre-vocalic lenis plosives may feature negative (or lead) VOT; in other words, there may be vocal folds vibrations during the closure phase, with the full vowel unfolding shortly after the release (Docherty 1992). This realization is observed especially in slow, careful and deliberate pronunciation, and is completely missing in rapid speech (Roach 2009). The other possible realization is with a shortlag positive VOT, i.e. with voicing starting at or shortly after the release of the closure, a pattern typical of Czech voiceless plosives. In studies by Smith (1978) and Westbury (1979), each realization was observed in about $50 \%$ of the pooled data, but the individual participants exhibited preference for one or the other while not using either exclusively (as cited in Docherty 1992: 31). In the more recent study by Docherty (1992), however, the short-lag realization of lenis plosives was demonstrated to prevail, with some participants not displaying a single token of prevoiced realization.

With regard to Czech voiced plosives, it is not completely clear what the situation is, as not many studies are available. Machač's (2006) otherwise comprehensive treatise of Czech plosives excludes post-pausal word-initial voiced plosives from the analysis. Since both Machač (2006) and, in a closely related work (also excluding post-pausal word-initial voiced plosives), Šimek (2011) consider voiced/ voiceless contrast as a very stable feature of Czech plosives, it may be reasonable to assume that $/ \mathrm{b}, \mathrm{d}, \mathrm{g} / \mathrm{in}$ word-initial positions exhibit prevoicing. This has recently been confirmed in an experimental study of Podlipský and Šimáčková (2018), in which the participants produced the vast majority of word-initial /d/ with prevoicing.

To summarize, the English word-initial pre-vocalic fortis plosives feature a long-lag positive VOT, while the Czech ones display a short-lag positive VOT. As regards lenis plosives, the English /b, d, g/ display either a short-lag positive VOT, or a negative VOT (prevoicing), with a tendency towards the former. Their Czech counterparts, on the other hand, presumably show a strong tendency to prevoicing.

\section{Hypotheses}

The characteristics of Czech and English word-initial plosives outlined above, as well as the previous findings lead to the following hypotheses regarding the changes in VOTs in the Anglophone expatriates living in the Czech Republic.

1. The expatriates will exhibit shortening of VOTs in word-initial fortis plosives as compared to the control group.

2. The expatriates will exhibit more prevoicing in word-initial lenis plosives as compared to the control group. 


\section{Method}

\subsection{Participants}

Expatriates: 10 Americans and 8 British (from various regions of the two respective countries) living in the Czech Republic, $M_{\text {age }}=38, S D_{\text {age }}=8.7$, raised in monolingual families, with length of residence in the Czech Republic for over 1 year $\left(M_{L O R}=9.5\right.$ years, $S D_{L O R}=6.9$ ), working mostly as teachers of English or in IT/corporate jobs, with varying degrees of L2 Czech proficiency. The sample were recruited through personal contacts of the researcher and through snowballing. Verbal fluency test data (see below) were not obtained from 1 American participant.

L1 English Controls: 1 American and 15 British living in the UK, recruited through opportunity sampling, $M_{\text {age }}=34, S D_{\text {age }}=12$, raised in monolingual families. The participants were not monolingual: they all had studied one or more foreign languages in the course of their lives; however, no participant was an early bilingual, and only 4 reported having a good or very good proficiency in one of their foreign languages and using them on a regular basis at the time of data collection. Of these, 1 participant frequently used German with his L2 partner. Given that German voiceless plosives are aspirated in the same manner as the English ones, there is little risk of interference in the L1 English of this participant. On the other hand, German voiced plosives exhibit different voicing patterns than the English ones (Kleber 2018) and the potential L2 German interference in this control group participant could not be completely ruled out (despite the findings of Stoehr et al. 2017); therefore his lenis plosives were not included in the analysis.

\subsection{Material and procedure}

The data for the present investigation were collected by means of two tasks: a word-list reading task and the verbal fluency test (VFT). The participants were recorded in a quiet office environment or in their homes using Zoom H4n Handy Recorder at the sampling frequency of $48 \mathrm{kHz}$. The participants were informed what the target variables were only after completing the two tasks.

Word-list reading task: The participants were presented with a word-list of 160 items, comprising 69 target items, i.e. monosyllabic lexemes with plosives in word-initial pre-vocalic position (see Appendix), items investigating other phonetic variables (not presented herein), and fillers. The participants were instructed to read the list in top-down, left-right direction, at a normal speed. All items were read in isolation (i.e. not as a part of a carrier phrase).

Verbal fluency test: VFT is a simple task which involves the participants naming as many lexical items from a certain category (e.g. animals, words starting with a certain letter) as they can come up with in 60 seconds' time (Schmid 2007). While this test is more typically used to detect signs of neurological impairment (e.g. Tombaugh, Kozak, and Rees 1999) or L1 attrition in the domain of lexicon 
(Schmid 2007), it is utilized here to elicit a less guarded, less carefully monitored speech style than reading a word list does (Labov 1966). In the four rounds of VFT, the participants were asked to provide lexical items from the following categories: "animals", "things you find in a supermarket", "words that start with the letter C", and "words that start with the letter T". The last two categories were designed specifically to elicit word-initial fortis plosives.

\subsection{Measurement}

The recordings were analyzed in PRAAT (Boersma and Weenink 2018) utilizing the following method to delimitate the boundaries of VOTs. The moment of the release of the closure, represented as the sudden onset of aperiodic noise in the waveform and a corresponding dark vertical strip in the spectrogram, was set as the zero point (Skarnitzl 2011). Tokens in which the burst was missing or was unclear were excluded from the analysis. In the presence of multiple bursts, the first burst was set as the boundary, as recommended by Skarnitzl (2011). For positive VOTs, the onset of vocal fold vibrations was delimitated at the beginning of periodicity of the waveform; in other words, at the onset of the first complete period following the aperiodic noise signal (Skarnitz 2011). The duration (in ms) of the speech segment within the two boundaries was then recorded as the positive VOT for fortis plosives. To assess the reliability of this measurement, $12 \%$ of word-list fortis plosive VOTs were remeasured and then correlated with the original values, indicating high reliability at $r=.98, p<.001$.

The situation proved to be more complex with negative VOTs (i.e. with prevoicing) in lenis plosives. In some instances the quality of the recording did not allow to establish the exact point when the pre-release voicing (represented by the voicing bar at the bottom of the spectrogram and regular pulses in the waveform) started. Additionally, in some instances the voicing ceased before the release of the closure. Therefore, rather than to measure the duration of the negative VOTs, only the presence/absence of pre-release voicing was recorded. In order to categorize a lenis plosive as prevoiced, the following criteria had to be met: the voicing was present within $100 \mathrm{~ms}$ before the release, and, at the same time, was present for at least $60 \%$ of the time in the period from the onset of voicing to the release. The tokens for which voicing from the previous word in the list continued without interruption until the burst of the word-initial lenis plosive (i.e. there was no pause preceding the target token) were excluded from the analysis. A reliability check was performed on $12 \%$ of word-list reading task data, with $99 \%$ agreement in categorization of the lenis plosives as prevoiced, shortlag, or exluded. 


\section{Results}

\subsection{Word-list fortis plosives}

After discarding 5 tokens due to missing or unclear release of the closure, in total 1,185 tokens of post-pausal pre-vocalic fortis plosives entered the analysis. Table 1 below displays the number of tokens, group means and standard deviations for the individual fortis plosives for both groups. In order to examine the potential interference of native variety (British, American English), the table displays data for expatriate British and expatriate Americans in separate columns, as well as pooled data across the two groups. As regards the single American participant in the control group, it was decided not to display her data separately.

\begin{tabular}{|l|l|c|c|c|c|}
\cline { 3 - 6 } \multicolumn{2}{l|}{} & \multicolumn{3}{c|}{ Expatriates } & Controls \\
\hline \multirow{2}{*}{ Plosive } & $\begin{array}{c}\text { British } \\
\mathrm{N}=8\end{array}$ & $\begin{array}{c}\text { Americans } \\
\mathrm{N}=10\end{array}$ & $\begin{array}{c}\text { pooled } \\
\mathrm{N}=18\end{array}$ & $\begin{array}{c}\text { pooled } \\
\mathrm{N}=16\end{array}$ \\
\hline \multirow{3}{*}{$/ \mathrm{p} /$} & $N_{\text {tokens }}$ & 103 & 130 & 233 & 207 \\
& $M$ & 62 & 64 & 63 & 78 \\
& $\mathrm{SD}$ & 9 & 12 & 11 & 18 \\
\hline \multirow{4}{*}{$/ \mathrm{k} /$} & $N_{\text {tokens }}$ & 111 & 140 & 251 & 222 \\
& $M$ & 79 & 82 & 81 & 90 \\
& $\mathrm{SD}$ & 13 & 8 & 10 & 22 \\
\hline \multirow{3}{*}{$/ \mathrm{t} /$} & $N_{\text {tokens }}$ & 64 & 80 & 144 & 128 \\
& $M$ & 85 & 86 & 85 & 99 \\
& $\mathrm{SD}$ & 8 & 13 & 11 & 24 \\
\hline
\end{tabular}

Table 1. Fortis plosives in word-list reading task: descriptive statistics

The comparison of British and American expatriates (first two columns of Table 1) shows only a minute difference in mean VOTs. Subsequent series of t-test confirmed that the differences are not statistically significant $(/ \mathrm{p} /: t(16)=0.31$, $p=.76 ; / \mathrm{k} /: t(16)=0.65, p=.53 ; / \mathrm{t} /: t(16)=0.182, p=.86)$. The control group consistently exhibits higher VOT means than the expatriate group.

Figure 1 below displays the box plot of individual plosives by the two groups. It becomes apparent that the VOTs of the individual plosives do not follow the typical pattern reported in earlier studies (see Docherty 1992 for a comprehensive overview, but also Major, 1992, for an L1 attrition study of VOTs): contrary to the previous findings, $/ \mathrm{t} /$ exhibits the longest VOTs. This may be caused by different vowel environments of the $/ \mathrm{t} /$ and $/ \mathrm{k} /$ test tokens. Alternatively, Docherty (1992: 173) suggests that "it is possible that in some cases the $/ \mathrm{t} /-/ \mathrm{k} /$ distributions are not in fact different," given the small differences in the $/ \mathrm{t} /$ and $/ \mathrm{k} /$ duration reported in the literature.

Another noticeable trend is that the expatriate group means are somehow more compact, i.e. with smaller overall as well as interquartile range. The control group, on the other hand, exhibit not only larger ranges, but also some outliers. The outliers are more than double the mean values reported by Docherty (1992) for Southern British English, and are located 1.9, 2.3 and 2.2 SD from the 
respective group means. The VOT measurements for the two control participants responsible for the outlier means were rechecked, and no apparent measurement error was found; the two participants simply consistently exhibited long VOT patterns. The sociolinguistic background of the two speakers also did not indicate any potential dialectal interference: both participants identified themselves as speakers of Southern British English. As regards the potential L2 influence, the female participant reported only a low degree of proficiency in her L2 and low amount of input and use. The male participant, on the other hand, had spent some time in Spanish and Portuguese speaking countries and reported a high degree of proficiency and regular input in both of these languages. However, both of these languages feature short-lag plosives (Macpherson 1975; Major 1992), so if any influence were to exhibit itself, it would most likely be shortening, not lengthening of VOTs (as documented by Major 1992, and Flege 1987). In summary, there was no apparent reason why these two control group participants should consistently exhibit such long VOTs, other than that they represent the idiolect of the two speakers. Even so, after careful consideration I decided to winsorize the data, i. e. replace the outlier participants' means with the next highest value which is not an outlier (Field 2014), so as not to influence the control group's overall means. Thus, the outlier / $\mathrm{p} /$ mean VOT was changed from 113 $\mathrm{ms}$ to $108 \mathrm{~ms}$, the outlier / $\mathrm{k} /$ mean VOT of $140 \mathrm{~ms}$ to $116 \mathrm{~ms}$, and the outlier /t/ mean VOT of $152 \mathrm{~ms}$ to $137 \mathrm{~ms}$. Table 2 below details the newly obtained group means and SDs.

Figure 1. Boxplot of mean VOT of $/ p, k, t /$ in $m s$

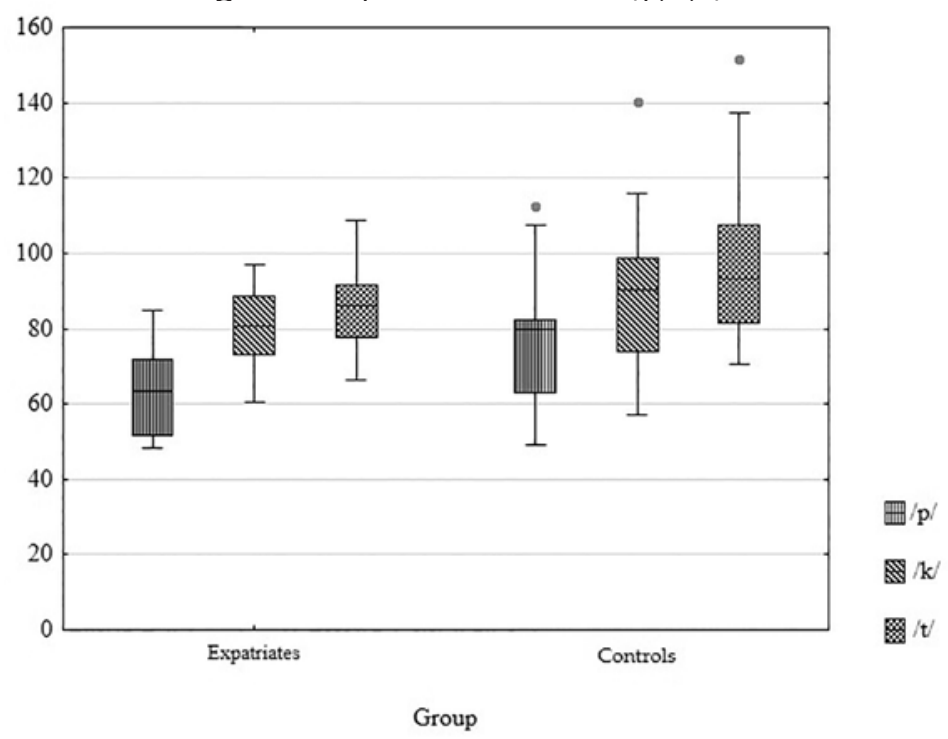




\begin{tabular}{|l|l|c|c|}
\hline \multicolumn{2}{|c|}{ plosive } & $\begin{array}{c}\text { Expatriates } \\
N=18\end{array}$ & $\begin{array}{c}\text { Controls } \\
\text { N }=16\end{array}$ \\
\hline \multirow{2}{*}{$/ \mathrm{p} /$} & $M$ & 63 & 77 \\
& SD & 11 & 18 \\
\hline \multirow{2}{*}{$/ \mathrm{k} /$} & $M$ & 81 & 89 \\
& $\mathrm{SD}$ & 10 & 18 \\
\hline \multirow{2}{*}{$/ \mathrm{t} / \mathrm{M}$} & $M$ & 85 & 98 \\
& SD & 11 & 23 \\
\hline
\end{tabular}

Table 2. Fortis plosives in word-list reading task: descriptive statistics after winsorization

These newly obtained values were examined as to the normality of distribution, using the visual inspection of Q-Q plots and a series of Shapiro-Wilk tests, which all indicated meeting the normal distribution requirement. The assumption of homogeneity of variances was tested using Levene's test, which uncovered unequal variances in case of $/ \mathrm{t} /$ means. A series of independent t-tests was then performed to compare the means exhibited by the two groups. A Welch's t-test for unequal variances was utilized for $/ \mathrm{t} /$. The results are displayed in the Table 3 below, showing significant and marginally significant differences in $/ \mathrm{p} /$ and $/ \mathrm{t} /$ mean VOTs of the two groups with large effect sizes respectively, as indicated by Hedge's $g$.

\begin{tabular}{|c|c|c|l|c|}
\hline plosive & $d f$ & $t$ & \multicolumn{1}{|c|}{$\boldsymbol{p}$} & Hedge's $\mathbf{~}$ \\
\hline$/ \mathrm{p} /$ & 32 & 2.80 & .009 sig. & .93 \\
\hline$/ \mathrm{k} /$ & 32 & 1.59 & .121 non-sig. & - \\
\hline$/ \mathrm{t} /$ & 20.9 & 2.07 & .051 marginally sig. & .72 \\
\hline
\end{tabular}

Table 3. Word-list reading: $t$-test results for fortis plosives mean VOTs

Given the fact that speakers of American English were unequally represented in the two groups (there being only 1 American English speaker within the control group), it was decided to conduct another series of t-tests, this time with British speakers only, so as to screen out the potential American English bias despite the fact that the within-group tests failed to show any significant difference between the two expatriate subgroups. Table 4 below displays the descriptive statistics (with winsorized means as utilized above) for speakers of British English only. Upon comparison with Table 2 above, it becomes apparent that the means do not change dramatically after removing the American English VOT values.

\begin{tabular}{|l|l|c|c|}
\hline \multicolumn{2}{|c|}{ plosive } & British expatriates & British controls \\
& $N=8$ & $N=15$ \\
\hline \multirow{2}{*}{$/ \mathrm{p} /$} & $M$ & 62 & 77 \\
& SD & 9 & 19 \\
\hline \multirow{2}{*}{$/ \mathrm{k} /$} & $M$ & 79 & 89 \\
& SD & 13 & 19 \\
\hline \multirow{2}{*}{$/ \mathrm{t} /$} & $M$ & 85 & 99 \\
& SD & 8 & 23 \\
\hline
\end{tabular}

Table 4. Fortis plosives in word-list reading task: British participants only 
For the purposes of the t-test the means were examined as to the normality of distribution by a visual inspection of Q-Q plots and a series of Shapiro-Wilk tests, which all indicated meeting the normal distribution requirement. The assumption of homogeneity of variances was tested using Levene's test, which again uncovered unequal variances in case of $/ \mathrm{t} /$ means. A series of independent $\mathrm{t}$-tests was then performed to compare the means exhibited by the two groups; Welch's $\mathrm{t}$-test for unequal variances was utilized for $/ \mathrm{t} / \mathrm{VOTs}$. The results are displayed in the Table 5 below, showing significant differences in $/ \mathrm{p} /$ and $/ \mathrm{t} /$ mean VOTs of the two groups with large effect sizes, as indicated by Hedge's $g$.

\begin{tabular}{|c|c|c|l|c|}
\hline plosive & $d f$ & $t$ & \multicolumn{1}{|c|}{$p$} & Hedge's $\mathbf{~}$ \\
\hline$/ \mathrm{p} /$ & 21 & 2.09 & .049 sig. & .88 \\
\hline$/ \mathrm{k} /$ & 21 & 1.32 & .2 non-sig. & \\
\hline$/ \mathrm{t} /$ & 19 & 2.09 & .05 sig. & .7 \\
\hline
\end{tabular}

Table 5. Word-list reading: t-test results for fortis plosives mean VOTs, British participants only

\subsection{Verbal fluency test fortis plosives}

Given the less controlled nature of the task, individual participants produced unequal numbers of lexical items with word-initial plosives. Additionally, the target plosives appeared in varying phonetic environments. The sensitivity of VOT to its surrounding phonetic context (e.g. Higgins, Netsell, and Schulte 1998) would in high probability occlude any kind of L2 interference such as was seen in the preceding analysis, where the phonetic context was kept constant for each participant. However, there was one single lexeme which every participant utilized in the course of the VFT, namely the lexeme cat; therefore, it was possible to compare the two groups' VOTs as produced when saying this particular lexeme. In the cases when the participants produced this word more times than once, the shortest VOT was included in the analysis. No other lexeme was uttered by more than $50 \%$ of participants.

Figure 2 below displays mean VOTs for the word cat. The expatriate group again exhibits a more restricted range than the control group. No outliers are present, but the upper whisker of the control group reaches to the region of 170 ms. Closer inspection of the data revealed that the participant responsible for this token consistently exhibited longer than average VOTs but without sounding overly hesitant or noticeably distinct. Given that the token does not lie in the outlier range, it was decided not to exclude it from the analysis. Table 6 below displays the descriptive statistics for both groups. As can be observed, both median and mean are higher for the control group. Further, the British and American expatriates' VOTs do not differ greatly, which is further confirmed by a nonsignificant independent t-test $(t(15)=0.3, p=.77)$. 
Figure 2. Boxplot of cat VOTs in ms

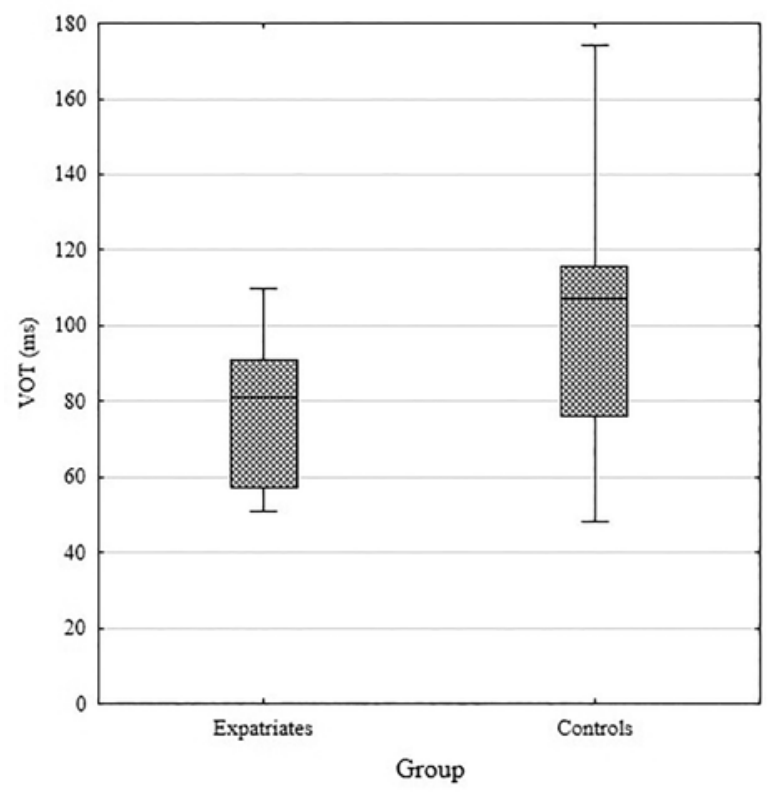

\begin{tabular}{|c|c|c|c|c|c|}
\hline \multirow{2}{*}{\multicolumn{2}{|c|}{ plosive }} & \multicolumn{3}{|c|}{ Expatriates } & \multirow{2}{*}{$\begin{array}{c}\text { Controls } \\
\text { pooled } \\
N=16\end{array}$} \\
\hline & & $\begin{array}{c}\text { British } \\
N=8\end{array}$ & $\begin{array}{c}\text { Americans } \\
N=9\end{array}$ & $\begin{array}{c}\text { pooled } \\
N=17\end{array}$ & \\
\hline$/ \mathrm{k} /$ in cat & $\begin{array}{l}M \\
S D\end{array}$ & $\begin{array}{l}80 \\
20\end{array}$ & $\begin{array}{l}77 \\
18\end{array}$ & $\begin{array}{l}78 \\
18\end{array}$ & $\begin{array}{l}103 \\
35\end{array}$ \\
\hline
\end{tabular}

Table 6. Verbal fluency test: cat VOT descriptive statistics

Next, the pooled cat / k/ VOTs were examined as to the normality of distribution, using the visual inspection of Q-Q plots and a Shapiro-Wilk test, which indicated meeting the normal distribution requirement. The assumption of homogeneity of variances was tested using Levene's test, the result of which indicated that the assumption was met in the sample. An independent t-test was then conducted, indicating a statistically significant difference between the two groups' means, $t(31)=2.54, p=.016$, with a large effect size as indicated by Hedge's $g=.88$. When controlling for nationality, however, the t-test does not indicate any difference between the two groups $(t(21)=1.64 ; p=.12)$.

\subsection{Word-list lenis plosives}

After discarding 97 tokens (10\% and $8 \%$ of tokens produced by the two respective groups) according to the criteria described in the Method section of the present articles, altogether 992 tokens ( 535 by the expatriate group, 457 by the control group) of pre-vocalic word-initial lenis plosives obtained through the word-list reading task remained for the analysis. Figure 3 below displays the percentage of 
negative (prevoiced) and positive short-lag VOTs as produced by the two respective groups.

Figure 3. Percentage of negative and short-lag VOTs produced by the expatriates and controls

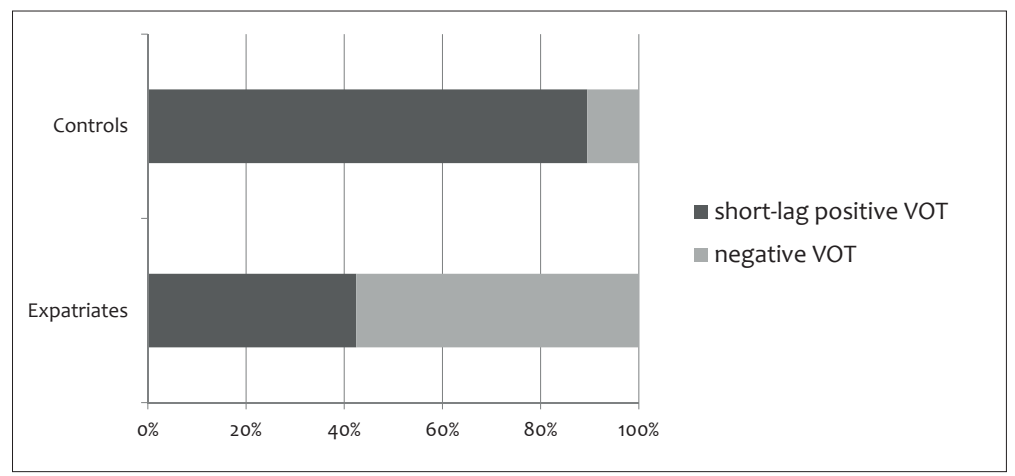

As can be observed from Figure 3, the expatriate group exhibit a higher proportion of negative VOTs in lenis plosives in the word-list reading task than the controls. This difference is statistically significant, as indicated by chi square test $\left(\chi^{2}(1, N=992)=237.3 ; p<.001\right)$, with a large effect size (Cramér's $\left.V=.49\right)$.

However, given the different composition of the two groups as regards the two main varieties of English, it was important to analyse the data in greater detail

Figure 4. Percentage of word-initial prevoiced lenis plosives in individual participants grouped by country of origin and experimental group

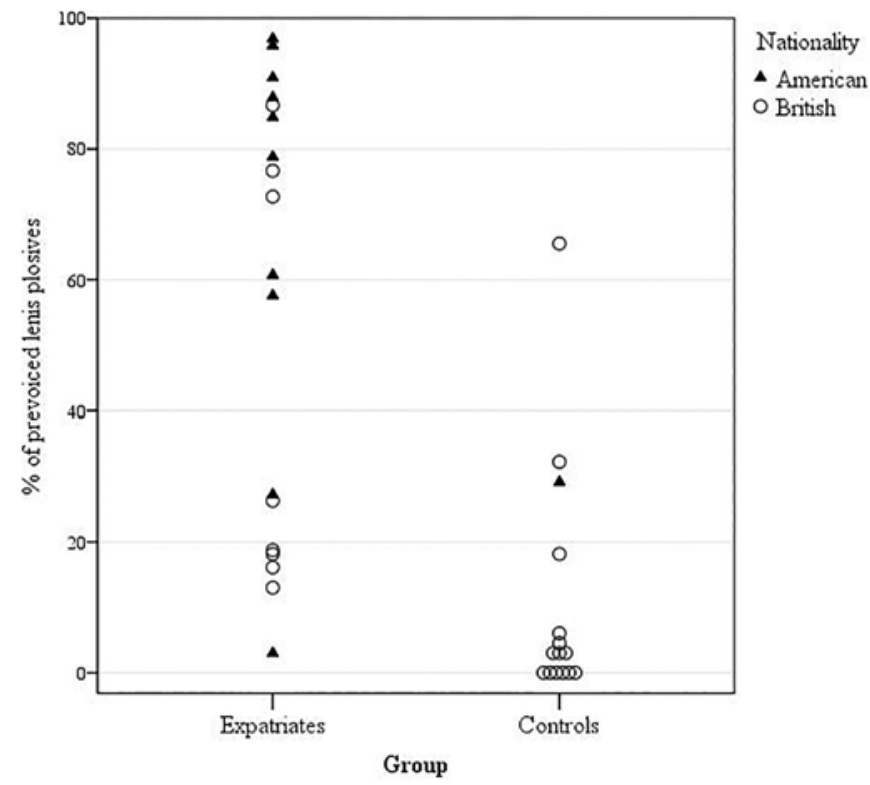


to be able to disregard the possibility that the variety of English is the decisive variable here, rather than cross-linguistic influence. Nevertheless, it is worth noting here that research on both British and American English (Docherty 1992 for an overview; Docherty 1992 for Southern British English; Davidson 2016 for American English) has shown that both prevoiced and short-lag realization of phrase initial /b, d, g/ exist in both varieties. The plot in Figure 4 breaks the dataset according to the group and country of origin, displaying the percentage of prevoiced plosives for each participant.

As can be observed from Figure 4 above, the members of the expatriate group consistently exhibit a higher percentage of prevoiced plosives. At the same time, Americans tend to have a higher percentage of negative VOTs than the British. To test whether the difference holds when the native dialect is controlled for, a chi-square test was conducted on British participants' data only, showing that British expatriates prevoice lenis plosives significantly more often than the British controls: $\left(\chi^{2}(1, N=664)=98.8 ; p<.001\right)$, with a medium effect size (Cramér's $V=.39)$.

\subsection{Verbal fluency test lenis plosives}

As stated above, the verbal fluency test presents a less formal task in which the participants recite items belonging to a certain category. Thus, while some participants may actually list identical items (the point in case being the lexeme $d o g$ here), it is by far not a rule. Further, the target phonemes appear in different phonetic contexts and the participants produce unequal numbers of the target phonemes.

That said, altogether 170 tokens of word-initial /b, g, d/ entered the analysis, 101 elicited from the expatriates, 69 from the controls. No tokens were elicited from 1 control group participant (the only American); thus, the control sample comprises only British English tokens. Figure 5 below displays the percentage of negative (prevoiced) and short-lag VOTs of the two respective groups as elicited through VFT.

Figure 5. Percentage of negative and short-lag VOTs produced by the expatriates and controls in VFT

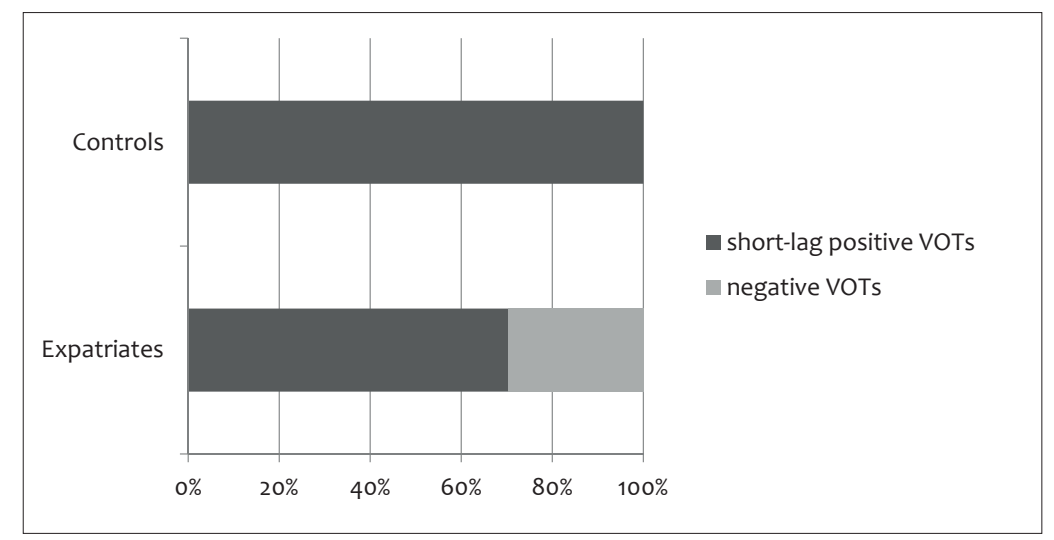


Figure 5 shows that the distribution is similar to that of the word-list reading task, with the expatriates exhibiting a larger proportion of pre-voiced word-initial lenis plosives, and the controls exhibiting no realization of prevoiced lenis plosive. However, upon closer inspection it turns out that the main contributors of negative VOTs in the expatriate group are the Americans, producing $80 \%$ of the prevoiced plosives, with only 3 British expatriates having produced prevoiced lenis plosives in this test. This, together with the fact that the participants produced unequal numbers of target items, does not allow for a meaningful statistical analysis comparing the expatriates and controls.

\section{Discussion}

Voice onset times in fortis plosives elicited through the word-list reading task consistently follow a pattern of lower means and medians in the expatriate group. Statistically speaking, the differences are significant for $/ \mathrm{p} /$ and $/ \mathrm{t} /$ with large effect sizes. These results are further partially supported by the analysis of VOTs in the lexeme cat as produced through a less controlled task, i.e. the verbal fluency test. Here again the expatriates display shorter mean in $/ \mathrm{k} /$ than the controls. In this analysis, however, the statistical difference does not hold when controlling for the nationality of the participants. This may be caused by a much lower number of tokens entering the analysis (only one per participant).

The results of the analysis support the L1 attrition hypothesis that VOTs in fortis plosives are shortened under the influence of Czech and/or Czech accented English. There is no evidence of phonetic category divergence or hypercorrection on the part of the expatriates. Notably, a certain kind of accent leveling can be observed in the expatriate data - the values fall within a much more restricted range with smaller standard deviations than the control group means although the expatriate group comprises speakers of both British and American English. However, it should be noted here that differences amounting to $10-20 \mathrm{~ms}$ in duration of the aspiration are virtually imperceptible to the naked ear; only some of the more extreme tokens might reach the just-noticeable level.

As regards lenis plosives, the quality of the recordings did not allow to measure the exact duration of negative VOTs. Instead, the plosives were categorized as either prevoiced or short-lag (i.e. with a short positive VOT). The expatriate group exhibited higher percentage of prevoiced lenis plosives as elicited through the word-list reading task. The American participants prevoiced lenis plosives more frequently than the British; however, the difference between the expatriates and controls held even when controlling for the native variety. It was not possible to conduct a meaningful statistical analysis on the verbal fluency test data, given the irregularities in the dataset caused by the less controlled nature of the task.

The fact that the expatriates exhibited the tendency towards the more laborious pronunciation of lenis plosives may be seen as surprising, given the findings of Stoehr et al. (2017) showing that Germans living in the Netherlands did not exhibit such shift. However, this tendency in the Anglophone expatriates may be further explained by the conscious effort they expend to be more easily comprehensible by 
their L2 interlocutors (i.e. Czech users of English), as prevoiced lenis plosives are a feature of careful, deliberate speech style (Roach 2009). One may ask why, by the same token, hypercorrection is also not observed in fortis plosives in the form of prolonged VOTs. This is not an easy question to answer, but it is conceivably harder to estimate and control the length of one's aspiration (especially with the phonetic category assimilation process at work) than it is to prevoice one's lenis plosives.

In conclusion, the results presented herein conform to the predictions of both Speech Learning Model (Flege 2002) and Communication Accommodation Theory (Beebe and Giles 1984). Both predict convergence towards the host country's language phonetic system, but through different mechanisms. SLM predicts convergence in the shared phonetic space when L1 and L2 phonemes are similar, and thus explains convergence in the expatriates who learn and use the L2 Czech. CAT, on the other hand, predicts convergence in situations when there is a strong motivation to appear likeable. Thus, even the expatriates who do not choose to learn and utilize the Czech language converge to Czech English, characterized by shorter VOTs in voiceless plosives, and possibly prevoicing of word-initial voiced plosives. It is conceivable that in some expatriates both mechanisms are at work at the same time, complementing each other. Disentangling the workings of the phonetic category assimilation (as postulated by Flege's SLM) and the accommodation strategy of convergence (as postulated by Giles's Communication Accommodation Theory) is a challenge for future research in this area. Further directions of future research include that of longitudinal (as opposed to cross-sectional) design, and the investigation of participant characteristics (e.g. language aptitude, occupation, personality traits) influencing the degree of L1 attrition in phonetics.

\section{References}

Beebe, Leslie M. and Howard Giles (1984) Speech-accommodation theories: A discussion in terms of second-language acquisition. International Journal of the Sociology of Language $46,5-32$.

Bergmann, Christopher, Amber Nota, Simone A. Sprenger and Monika S. Schmid (2016) L2 immersion causes non-native-like L1 pronunciation in German attriters. Journal of Phonetics 58, 71-86. https://doi.org/10.1016/j.wocn.2016.07.001

Boersma, Paul and David Weenink (2018) Praat: doing phonetics by computer (Computer software, version 6.0). www.praat.org

Cook, Vivian (2002) Background to the L2 user. In: Cook, Vivian (ed.) Portraits of the L2 User. Clevedon: Multilingual Matters, 1-28.

Cook, Vivian (2003) Introduction: The changing L1 in the L2 user's mind. In: Cook, Vivian (ed.) Effects of the Second Language on the First. Clevedon: Multilingual Matters, 1-18.

Chaudron, Craig (1988) Second Language Classrooms: Research on Teaching and Learning. Cambridge: Cambridge University Press.

Davidson, Lisa (2016) Variability in the implementation of voicing in American English obstruents. Journal of Phonetics 54, 35-50. https://doi.org/10.1016/j.wocn.2015.09.003

Dragojevic, Marko and Howard Giles (2014) Language and interpersonal communication: Their intergroup dynamics. In: Berger, Charles R. (ed.) Interpersonal Communication. Berlin: De Gruyter Mouton, 29-51. 
de Leeuw, Esther (2008) When your native language sounds foreign: A phonetic investigation into first language attrition (Doctoral dissertation). Queen Margaret University: Edinburgh. https://eresearch.qmu.ac.uk/handle/20.500.12289/7436

Docherty, Gerard J. (1992) The Timing of Voicing in British English Obstruents. Berlin: De Gruyter Mouton.

Dostert, Susan C. (2009) Multilingualism, L1 Attrition and the concept of 'Native Speaker' (Doctoral dissertation). Düsseldorf: Heinrich-Heine Universität. https://docserv.uniduesseldorf.de/servlets/DerivateServlet/Derivate-16416/Thesis_last\%20version.pdf

Field, Andy (2014) Discovering statistics using IBM SPSS Statistics, $4^{\text {th }}$ ed. Los Angeles: Sage Publications.

Flege, James Emil (1987) The production of "new" and "similar" phones in a foreign language: Evidence for the effect of equivalence classification. Journal of Phonetics 15(1), 47-65.

Flege, James Emil (2002) Interactions between native and second-language phonetic systems. In: Burmeister, Petra, Thorsten Piske and Andreas Rohde (eds.) An Integrated View of Language Development: Papers in Honor of Henning Wode. Trier: Wissenschaftlicher Verlag Trier, 217-244.

Flege, James Emil and James Hillenbrand (1984) Limits on phonetic accuracy in foreign language speech production. The Journal of the Acoustical Society of America 76 (3), $708-$ 721. https://doi.org/10.1121/1.391257

Gasiorek, Jessica, Howard Giles and Jordan Soliz (2015) Accommodating new vistas. Language E्F Communication 41, 1-5. https:// doi.org/10.1016/j.langcom.2014.10.001

Giles, Howard and Tania Ogay (2007) Communication Accommodation Theory. In: Whaley, Bryan B. and Wendy Samter (eds.) Explaining Communication: Contemporary Theories and Exemplars. Mahwah, NJ: Lawrence Erlbaum Associates, Inc., 293-310.

Higgins, Maureen B., Ronald Netsell, and Laura Schulte (1998) Vowel-related differences in laryngeal articulatory and phonatory function. Journal of Speech, Language, and Hearing Research 41 (4), 712-724. https://search.proquest.com/docview/232358788?accou ntid $=16531$

Jarvis, Scott and Aneta Pavlenko (2008) Crosslinguistic Influence in Language and Cognition. New York: Routledge.

Kleber, Felicitas (2018) VOT or quantity: What matters more for the voicing contrast in German regional varieties? Results from apparent-time analyses. Journal of Phonetics 71, 468-486. https://doi.org/10.1016/j.wocn.2018.10.004

Kupske, Felipe Flores and Ubiratã Kickhöfel Alves (2016) A fala de imigrantes brasileiros de primeira geração em Londres como evidência empírica para a língua como um Sistema Adaptativo Complexo. Revista Virtual de Estudos da Linguagem-ReVEL 14 (27), 173-203. http://www.revel.inf.br/files/e166bf461eec067bb8459c6617d5fd52.pdf

Labov, William (1966) The Social Stratification of English in New York City. Oxford: Center for Applied Linguistics.

Lisker, Leigh and Arthur S. Abramson (1964) A cross-language study of voicing in initial stops: Acoustical measurements. Word 20 (3), 384-422. https://doi.org/10.1080/00437 956.1964.11659830

Machač, Pavel (2006) Temporálni a spektrálni struktura českých explozív (Doctoral dissertation). Univerzita Karlova, Praha. http://hdl.handle.net/20.500.11956/7718

Macpherson, Ian Richard (1975) Spanish phonology: descriptive and historical. Manchester: Manchester University Press.

Major, Roy C. (1992) Losing English as a first language. The Modern Language Journal 76 (2), 190-208. https://doi.org/10.2307/329772

Mathesius, Vilém (1935) K výslovnosti cizích slov v češtině. Slovo a slovesnost, 1(2), 96-105.

Mayr, Robert, Sacha Price and Ineke Mennen (2012) First language attrition in the speech of Dutch-English bilinguals: The case of monozygotic twin sisters. Bilingualism: 
Language and Cognition 15 (4), 687-700. https://doi.org/10.1017/S136672891100071X Melen, Dušan (2010) Výslownost angličtiny na pozadi češtiny. Praha: Big Ben Bookshop.

Podlipský, Václav Jonáš a Šárka Šimáčková (2018). A disassociation of speech perception and production: Prevoicing as a phonetic cue to phonological voicing in Czech stops (Conference poster). Olinco 2018: Olomouc.

Porte, Graeme (1999) English as a forgotten language. ELT Journal 53 (1), 28-35. https:// doi.org/10.1093/elt/53.1.28

Pospíssilová, Andrea (2011) Aspiration of English plosives in Czech students of English studies (Bachelor's thesis). Univerzita Karlova: Praha. http://hdl.handle.net/20.500.11956/50351

Roach, Peter (2009) English Phonetics and Phonology: A Practical Course. Cambridge: Cambridge University Press.

Sancier, Michele. L. and Carol A. Fowler (1997) Gestural drift in a bilingual speaker of Brazilian Portuguese and English. Journal of Phonetics 25 (4), 421-436. https://doi. org/10.1006/jpho.1997.0051

Schmid, Monika S. (2007) The role of L1 use for L1 attrition. In: Köpke, Barbara, Monika S. Schmid, Merel Keijzer and Susan Dostert (eds.) Language Attrition: Theoretical Perspectives. Amsterdam: John Benjamins Publishing Company, 135-153.

Schmid, Monika S. (2011) Language Attrition. Cambridge: Cambridge University Press.

Schmid, Monika S. (2016) First language attrition. Language Teaching 49 (2), 186-212. https://doi.org/10.1017/S0261444815000476

Schmid, Monika S. and Kees de Bot (2004) Language attrition. In: Davies, Alan and Catherine Elder (eds.) The Handbook of Applied Linguistics. Malden: Blackwell Publishing Ltd., 210-234.

Skarnitzl, Radek (2011) Znělostni kontrast nejen v čěstině. Praha: Nakladatelství Epocha.

Snow, Catherine E., Roos Eeden and Pieter Muysken (1981) The interactional origins of foreigner talk: Municipal employees and foreign workers. International Journal of the Sociology of Language 28, 81-92. https://doi.org/10.1515/ijsl.1981.28.81

Stoehr, Antje, Titia Benders, Janet G. van Hell and Paula Fikkert (2017) Second language attainment and first language attrition: The case of VOT in immersed DutchGerman late bilinguals. Second Language Research 33 (4), 483-518. https://doi. org/ $10.1177 / 0267658317704261$

Šimek, Jaroslav (2011) Explozívy v češtině: temporální vlastnosti a variabilita prí realizaci (Master's thesis). http://hdl.handle.net/20.500.11956/33427

Thomas, Erik R. (2011) Sociophonetics: An Introduction. Houndmills: Palgrave Macmillan.

Tombaugh, Tom N., Jean Kozak and Laura Rees (1999) Normative data stratified by age and education for two measures of verbal fluency: FAS and animal naming. Archives of Clinical Neuropsychology 14 (2), 167-177. https://doi.org/10.1093/arclin/14.2.167

\section{Appendix}

Target word-list reading task items. Items in italics are adopted from Major (1992).

/p/ $(N=13):$ p, path, paw, pay, pet, pick, pig, poach, pod, pooch, pot, pub, pup

$/ \mathrm{k} /(N=14)$ : cab, cap, caught, coat, cob, cod, coo, cop, cot, cub, cup, $k, k e p t, k e y$

$/ \mathrm{t} /(N=8): t$, take, taught, Ted, teeth, toe, too, tot

/b/ $(N=17)$ : b, back, bag, bath, bay, bed, bet, boat, boot, botch, bought, buck (twice), bud, bug, bus, buzz

/g/ $(N=7)$ : gate, gawk, geese, get, goat, goo, got

/d/ $(N=9): d$, day, dead, do, dock, dog, dose, dough, doze 
MAGDA SučKová received her doctoral degree at Masaryk University, Brno, and she currently teaches linguistics and English for specific purposes at Brno University of Technology. She is interested in bilingualism, L1 attrition, and English language teaching. Her dissertation project focused on L1 attrition among Anglophone expatriates living in the Czech Republic.

Address: Magda Sučková, Brno University of Technology, Faculty of Electrical Engineering and Communication, Technická 3058/10, Královo Pole, 61600, Brno, Czech Republic. [email: suckova@feec.vutbr.cz] 